\title{
Pattern of Behavioural Problems in Children Attending Pediatric OPD
}

Dr. Swati Joshi, $\mathrm{MD}^{1}$, Dr. Krishna Kumar Mishra, $\mathrm{MD}^{2^{*}}$

${ }^{1}$ PGMO, Pediatrics, PC Sethi Hospital, Indore, Madhya Pradesh, India

${ }^{2}$ Senior Resident, Department of Psychiatry, MGM Medical College, Indore, Madhya Pradesh, India

DOI: $10.36347 /$ sjams.2020.v08i08.025

| Received: 11.08.2020 | Accepted: 25.08.2020 | Published: 28.08.2020

*Corresponding author: Dr. Krishna Kumar Mishra, MD

\section{Abstract}

Original Research Article

Introduction: Behavioural and psychological problems are one of the common problems in children attending Pediatric outpatient department. Identification of behavioural and psychological problems is most important not only to prevent further progression of illness but also for proper growth and development of the child. Objective: Aim of this study is to determine the proportion of various behavioural and psychological problems in children of age 6 to 12 years. Material \& methods: The study was conducted for a period of 3 months in 2018. Study was done on 500 children of 6-12 years attending Pediatric outpatient department in a tertiary care, teaching hospital. Children were screened using child behaviour check list (CBCL). Patients who were positive for behavioural problems in CBCL were assessed with DSM V criteria for any psychiatric illness. Results: In our study, we found that $7 \%$ children had behavioural and psychological problems. Enuresis was a very common problem in children between 6 to 12 years of age.11 children (2.2\%) had enuresis. Another common psychological problem found in our study was PICA. $1.8 \%$ children had PICA. Conclusion: Identification of behavioural and psychological disorders is most important so that preventive and treatment strategies can be planned at the earliest to prevent psychiatric morbidity in later life.

Keywords: Children Attending Pediatric Opd Behavioural.

Copyright @ 2020: This is an open-access article distributed under the terms of the Creative Commons Attribution license which permits unrestricted use, distribution, and reproduction in any medium for non-commercial use (NonCommercial, or CC-BY-NC) provided the original author and source are credited.

\section{INTRODUCTION}

Behavioural and psychological problems are one of the common problems in children attending pediatric opd. These problems are a cause of concern as they are often less addressed leading to impairment in child's development. Nearly $40-50 \%$ of these problems can persist and develop into childhood mental health problems. Some of these children may develop depression, substance abuse, bipolar mood disorders, antisocial personality disorders and other various psychiatric issues [1] Still large number of cases remains unreported [2]. Identification of behavioural and psychological problems is most important not only to prevent further progression of illness but also for proper growth and development of the child. Purpose of this study is identification and evaluation of various behavioural problems in children of age 6 to 12 years.

\section{ОВJECTIVE}

Aim of this study is to determine the proportion of various behavioural and psychological problems in children of age 6 to 12 years

\section{Material \& Methods}

The study was conducted for a period of 3 months in 2018. Study was done on 500 children of 612 years attending Pediatric outpatient department in a tertiary care, teaching hospital, Indore. Written informed consent was taken from parents of children participating in the study. Children having severe medical illness were excluded from the study. Children were screened using child behaviour check list (CBCL). Socio-demographic variables and Family history of psychiatric illness were recorded in the proforma. Patients who were positive for behavioural problems in CBCL were assessed with DSM V criteria for any psychiatric illness [3]. Statistical analysis was done using the SPSS software. 


\section{RESULTS}

Table-I: Prevalence of Psychiatric disorders in the study population

\begin{tabular}{|l|l|}
\hline No disorder & $\mathbf{4 6 5}(\mathbf{9 3 \%})$ \\
\hline ADHD & $7(1.4 \%)$ \\
\hline ASD & $2(0.4 \%)$ \\
\hline MR & $5(1 \%)$ \\
\hline PICA & $9(1.8 \%)$ \\
\hline ENURESIS & $11(2.2 \%)$ \\
\hline TIC DISORDER & $1(0.2 \%)$ \\
\hline
\end{tabular}

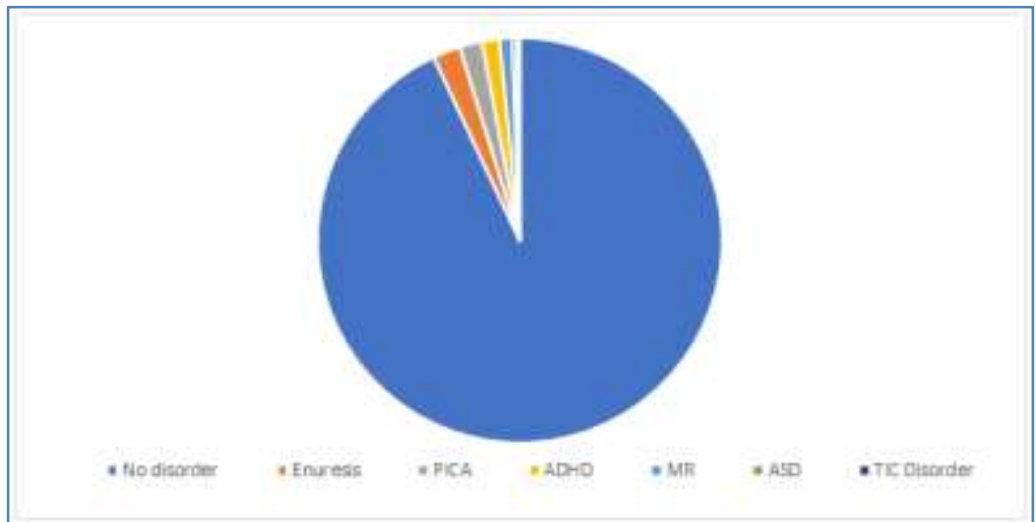

\section{DISCUSSION}

In our study, we found that $7 \%$ children had behavioural and psychological problems. Enuresis was a very common problem in children between 6 to 12 years of age. 11 children (2.2\%) had enuresis. Our findings are similar to the study done in school children in Chandigarh by Malhotra et al. [4]. In their study, $6.33 \%$ children were found to have psychiatric disorders and most prevalent disorder was enuresis. In our study also the most common problem was enuresis.

Another common psychological problem found in our study was PICA. 1.8\% children had PICA. This replicates the finding of study done by Srinath $e t$ al. [5] where they found $2 \%$ children had PICA. The low percentage of autistic spectrum disorder $(0.4 \%)$ in our study was also found in other studies in Bangladesh $[6,8]$.

\section{Conclusion}

Childhood behavioural problems have a significant negative impact on the individual, family and society. Behavioural and psychological problems are rising in our country so identification of these disorders is most important so that preventive and treatment strategies can be planned at the earliest to prevent psychiatric morbidity in later life.

\section{REFERENCES}

1. Kim-Cohen J, Caspi A, Moffitt TE, Harrington H, Milne BJ, Poulton R. Prior juvenile diagnoses in adults with mental disorder: developmental follow- back of a prospective-longitudinal cohort. Archives of general psychiatry. 2003 Jul 1;60(7):709-17.

2. Bansal PD, Barman R. Psychopathology of school going children in the age group of 10-15 years. International journal of applied and basic medical research. 2011 Jan;1(1):43.

3. Edition, F. (2013). Diagnostic and statistical manual of mental disorders. Am Psychiatric Assoc.

4. Malhotra S, Kohli A, Arun P. Prevalence of psychiatric disorders in school children in Chandigarh, India. Indian Journal of Medical Research. 2002 Jul 1;116:21.

5. Srinath S, Girimaji SC, Gururaj G, Seshadri S, Subbakrishna DK, Bhola P, Kumar N. Epidemiological study of child \& adolescent psychiatric disorders in urban \& rural areas of Bangalore, India. Indian Journal of Medical Research. 2005 Jul 1;122(1):67.

6. Mullick MS, Goodman R. The prevalence of psychiatric disorders among 5-10 year olds in rural, urban and slum areas in Bangladesh. Social psychiatry and psychiatric epidemiology. $2005 \mathrm{Aug}$ 1;40(8):663-71

7. Jahan NA, Rahman AH, Choudhury S, Chowdhury KP, Wahab MA, Rahman F. Prevalence of mental disorders, mental retardation, epilepsy and substance abuse in children. 2009.

8. Alam MF, Hasan N, Ali M, Azad MC, Bashar K, Akhter F. Multi-axial diagnoses of child and adolescent psychiatric disorders in inpatient department of National Institute of Mental Health, Dhaka. Bang J Psychiatry. 2004;18(2):55-65. 